\title{
Chicken Ascariasis and Heterakiasis: Prevalence and Associated Risk Factors, in Gondar City, Northwest Ethiopia
}

\author{
Abrham Ayele Tsegaye Jnr (D) \\ Abeba Adino Miretie ${ }^{2}$ \\ 'University of Gondar, Department of \\ Paraclinical Studies, Gondar, Amhara \\ Regional State, Ethiopia; ${ }^{2}$ Universities of \\ Gondar, College of Veterinary Medicine \\ and Animal Sciences, Gondar, Amhara \\ Regional State, Ethiopia
}

\begin{abstract}
Introduction: Chicken nematodes are found all over the world. Ascaris and Heterakis are among the cosmopolitan chicken nematodes. In different parts of Ethiopia, these parasites have long been thought to be the leading cause of illness and loss of productivity. However, there has been little research on their burden in Gondar city; hence, this study was carried out to establish a realistic estimate of the prevalence of Ascariasis and Heterakiasis in chickens. Methodology: A cross-sectional study was undertaken in Gondar city, North West Ethiopia, from November 2019 to May 2020 to evaluate the prevalence and different related risk factors of chicken Ascaris and Heterakis infections. A total of 384 hens were tested utilizing the faecal flotation technique, with 170 native and 214 alien varieties. During the collection of faecal samples, the breed, age, production system, and feces consistency of chickens were all taken into account.

Results: One hundred seventy-one $(44.5 \%)$ of the total (384) investigated feces tested positive for at least one of these parasite illnesses. The parasite's prevalence was influenced by age, breed, and the type of production technique used. A higher infection rate was observed in the younger $(68.9 \%)$ indigenous $(67.1 \%)$ chickens reared under the extensive production system $(46.9 \%)$.

Discussion and Conclusion: The prevalence of ascariasis and heterakiasis was nearly half percent in this study, even though the study was conducted in dry season, which is relatively unfavorable to parasites living in the environment and it specified only on the two common chicken ascaris nematodes. This study strongly suggested that Ascaris and Heterakis parasites were serious problems for chickens in Gondar city, and appropriate control strategies needed to be advised.
\end{abstract}

Keywords: chicken, ascaris, heterakis, prevalence, Gondar city, Ethiopia

\section{Introduction}

Poultry production is considered the chief source of high-quality protein in human food. Ethiopia's total poultry production is estimated as 56.5 million, of which about $99 \%$ are raised under the traditional backyard management system. ${ }^{1}$ Despite the presence of a large number of chickens in Ethiopia, their contribution to the national economy or benefit is very limited due to nutritional limitations and infectious diseases. ${ }^{2}$

In Ethiopia, many poultry diseases have been reported, mostly in exotic birds kept intensively. Newcastle's disease, coccidiosis, salmonellosis, chronic respiratory disease (CRD), and nutritional inadequacies are the leading causes of economic losses in such flock. ${ }^{3}$
Jnr

Email ayeleabrham23@gmail.com

abrham.ayele@uog.edu.et 
Among infectious diseases in chickens reared extensively, helminthosis is very common due to chickens having a wide range of feeding habits, including feeding on feces, which may carry infective stages of parasites. Feed availability to scavenging chickens is inadequate both in quantity and in quality, and thus, predisposing them to parasitic infections is increased. The presence of a few parasites does not usually cause a problem. However, large numbers can have a devastating effect on growth, egg production, and overall health. ${ }^{4}$

From the parasitic diseases of the world chicken industry, the nematode parasite shares major problems which are characterized by ruffled feathers, loss of appetite, poor growth, and reduced egg production. ${ }^{5}$ Ascaris and Heterakis are among the most important worldwide distributed nematodes too. They are very common in alternative production systems and the case of multifactorial diseases may contribute to substantial economic losses. Infections with $A$. galli are associated with higher feed conversion rates and a decrease in body weight gain and egg production. The main economic importance of $H$. gallinarum is due to its role as a carrier of Histomonas meleagridis (H. meleagridis), a protozoan parasite that induces blackhead disease. ${ }^{5}$

Ascaridia galli is a nematode parasite occurring in all parts of the small intestine, while H. gallinarum is in the cecum. However, these different roundworms do have very similar egg and life cycles and are widely distributed in different parts of the world. ${ }^{1}$ Accurate identification of these parasites at the species level may give directions to treat and control parasitic infection and eliminate the paratenic hosts such as grasshoppers or earthworms, and, therefore, break their life cycle. ${ }^{5}$ The prevalence and intensity of parasite infections may be influenced by several factors, such as the distribution of intermediate hosts and their infection rate, and the number of infective parasite eggs or larvae. Host factors such as age, sex, and breed can also influence the infection. ${ }^{6}$

Research was exhausted about the prevalence of parasites in chickens in Ethiopia. According to Ashenafi and Eshetu, ${ }^{6}$ the prevalence of parasitic infections in central Ethiopia reaches $90.21 \%$. Tesfaheywet et $\mathrm{al}^{7}$ in Haramya reported an overall prevalence of $41.4 \%$ for helminth parasites, and Beyene et al $^{1}$ found a prevalence of $46.9 \%$ for gastrointestinal nematode parasites. But it is limited by its coverage in Ethiopia and it does not indicate the whole picture of the prevalence in Ethiopia, especially in the central Gondar zone.

Ascaris and Heterakis have been considered to be the most important problems for local chickens and are major causes of ill-health and loss of productivity in different parts of Ethiopia. ${ }^{4}$ The study areas have a higher poultry population, but there was a shortage of information regarding the prevalence of intestinal parasites in chickens. Therefore, to design effective preventive and control strategies, it is very essential to know about the parasites burden. This study was undertaken to provide baseline data on the prevalence of Ascaris and Heterakis types of parasites in chickens in Gondar city.

\section{Methods and Materials Study Area}

This research was conducted in Gondar, which is a city and woreda in the Amhara Regional state, Ethiopia. It is located at $12^{\circ} 36^{\prime} \mathrm{N} 37^{\circ} 28^{\prime} \mathrm{E}$. Gondar is approximately $742 \mathrm{~km}$ from Ethiopia's capital, Addis Ababa (Figure 1). Gondar is to the north of Lake Tana and southwest of the Simien Mountains. With an annual average of $1172 \mathrm{~mm}$ and a mean annual temperature of $20^{\circ} \mathrm{C}$, the rainfall pattern is bimodal. According to the Central Statistical Agency of Ethiopia's (CSA) national census, Gondar had a total population of 500,788 , with 300,000 men and 200,788 women. ${ }^{8}$ The climate in Gondar is weynadega, and the city has a mixed agricultural system. Cattle, sheep, goat, equines, and poultry are the main reared animals. Both intensive and extensive types of poultry husbandry systems are practiced in Gondar town where the intensive one is mainly concentrated on exotic breeds of chicken.

Gondar is home to the University of Gondar, which includes Ethiopia's main faculty of medicine. The Parasitology Laboratory at the University of Gondar College of Veterinary Medicine and Animal Sciences (UoG-CVMASc) was used to identify the parasites.

\section{Study Period and Population}

The research was carried out from November 2019 to May 2020, covering Ethiopia's three seasons (excluding the fourth, ie summer). However, because only one season was fully included in this cross-sectional investigation, it was unable to establish season-based prevalence. The study included both male and female hens of various age groups reared in intensive and extensive management styles. Study chickens were divided into two age groups: young (under 6 months) and adults (above 6 months). ${ }^{9}$

The chickens tested came from three sources: from the local markets, from the home-held hatching, and from the commercial hatchery. 


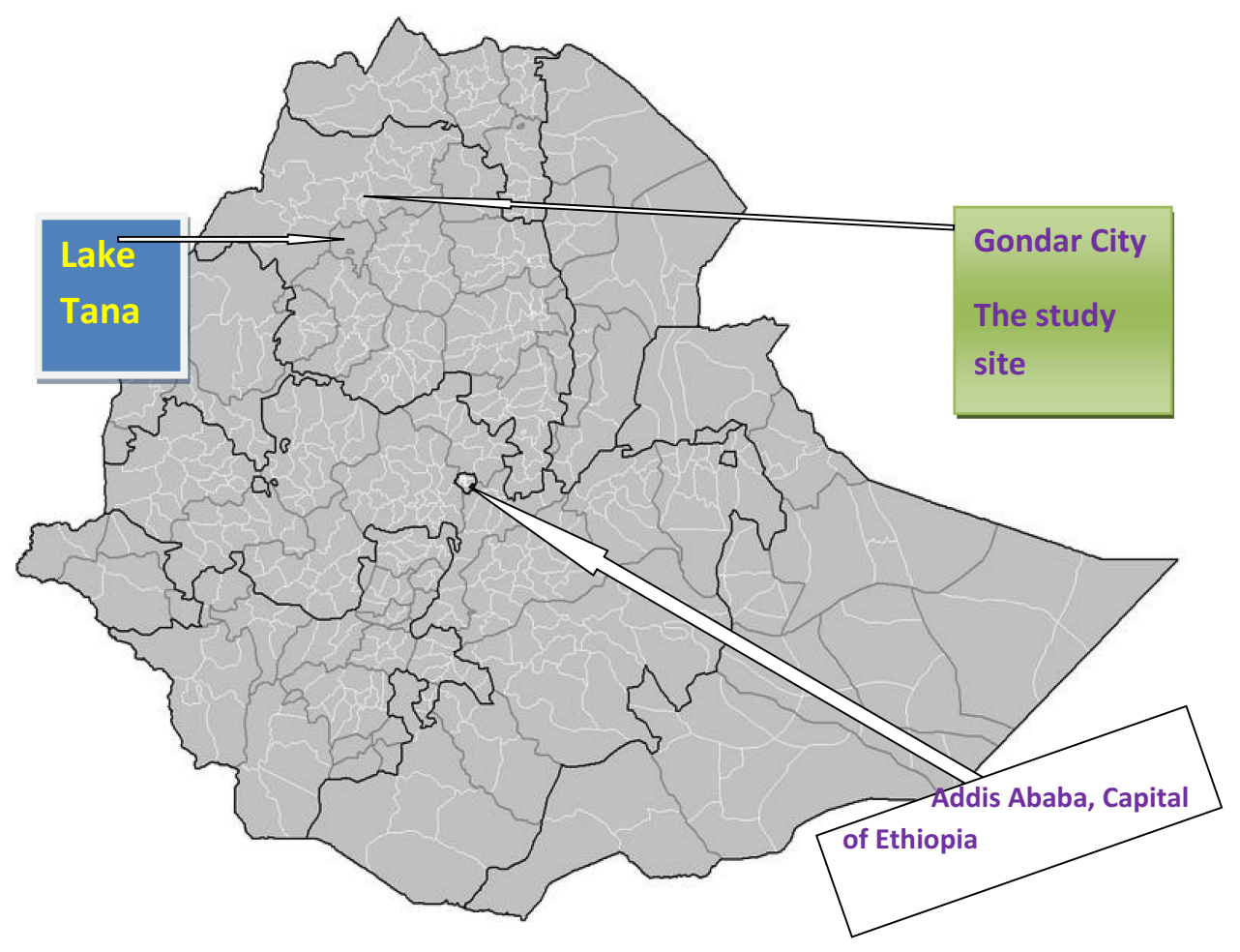

Figure I Gondar City, The study site.

\section{Study Design and Sample Size Determination}

A cross-sectional study design with a two-stage cluster sampling procedure was used. From a total of 21 kebeles identified in Gondar city, three kebeles were chosen randomly. Then, utilizing the highway and the names of the communities, they were further separated into villages. Then, using a lottery system, two villages from one kebele (for a total of six villages) were chosen. A systematic random sampling system was used to select individual chickens up to the amount fulfilled to the maximum sampling size using the standard formula described by Thrusfield. Ten household poultry owners per village (a total of 60 households) were taken as samples, and a systematic random sampling system was used to select individual chickens up to the amount fulfilled to the maximum sampling size using the standard formula described by Thrufield ${ }^{10}$ that is as follows:-

$$
\mathrm{N}=\frac{\mathrm{Z}^{2} * \mathrm{P}_{\exp } *(1-\mathrm{Pexp})}{\mathrm{d}^{2}}
$$

Where: $\mathrm{N}=$ required sample size, $\mathrm{Z}=(1.96)^{2}$ at $95 \%$ confidence interval, $\mathrm{P}_{\exp }=$ expected Prevalence and $\mathrm{d}=$ desired absolute error (0.05). Since there were no previously published reports from the study site, the expected prevalence was considered as 50\%, with 5\% desired absolute precision and $95 \%$ confidence level. Therefore, based on this formula 384 chickens were selected for this study.

\section{Sample Collection and Parasitic Eggs Identification Techniques}

Aseptically, fresh feces samples were taken straight from the poultry cloaca with a sterile spatula. The spatula tip containing the feces was then put into a clean sampling container in the icebox. The material was then brought to the veterinary parasitology laboratory at the University of Gondar and kept in a +4 refrigerator until it was processed for a faecal flotation procedure. ${ }^{11}$

Standard protocols for flotation utilizing saturated sodium chloride $(\mathrm{NaCl})$ as the flotation fluid were used to evaluate faecal samples for the detection of ascaris and heterakis eggs in the laboratory. ${ }^{12}$ A tiny amount of checked faecal sample was thoroughly mixed with $10 \mathrm{~mL}$ of flotation solution and placed into a test tube. To fill the tube to the top, more flotation solution was poured into suspension. On top of the surface, a cover slip was placed and left for 10-15 min. Cover slip was carefully placed into a microscope slide and viewed under a microscope after that. Eggs of nematodes were identified using the keys and descriptions provided by Soulsby, ${ }^{13}$ and Taylor et al. ${ }^{14}$ Ellipsoidal-shaped embryonated parasitic 
eggs in chicken faeces having thick shell are considered as positive for heterakiasis and/or ascariasis.

\section{Data Management and Analysis}

The collected data were coded and stored in Microsoft Excel spreadsheets. Data analysis was made using SPSS version 20 to summarize the raw data. Chi-square statistics were used to describe the contribution risk factors with parasite prevalence. A statistical significance level was set at $P<0.05$ at a $95 \%$ confidence level.

\section{Ethical Clearance}

This research is part of a DVM thesis. As a result, we veterinarians did our best to conduct this investigation and publish it in an ethical manner. Research and Ethical Committee of University of Gondar, College of Veterinary Medicine and Animal Sciences provided ethical clearance, and authorization consent was sought from each poultry farm owner. Before giving the questionnaire, each participant's signed agreement was obtained after obtaining permission.

\section{Results}

\section{Morphological Features of the Recovered Eggs}

Ellipsoidal-shaped embryonated parasitic eggs in chicken faeces having thick shell are considered positive for heterakiasis and/or ascariasis.

\section{Over All Prevalence}

With an overall incidence of $44.5 \%, 171$ of the 384 investigated faecal samples obtained from chickens were determined to be positive for Ascaris and Heterakis eggs (Table 1). During the prevalence investigation, many risk factors such as age, breed, and production system were investigated. One hundred and seventy of the 384 chickens were native, while the other 214 were exogenous breeds. A breed-by-breed examination revealed that 114 (67.1\%) of indigenous chickens and 57 (36.3\%) of foreign chickens tested positive. It differed significantly $\left(X^{2}=62.73\right.$, $P=0.00$ ). Forty one of the total examined chickens were reared in an intensive production system and the remaining 343 were extensive. Of this number, $24.4 \%$ of chickens were positive for GIT helminth infection and $46.9 \%$ of extensively reared chickens were also positive for the infection. The production system factor showed that it has a significant $\left(X^{2}=7.54, P=0.006\right)$ effect on the occurrence of infection.

Most (294) chickens were above 5 months old and of this number, $31.1 \%$ were positive for either heterakis and/ or ascarid parasites. Sixty-two of the 90 young chickens were also positive for this infection. This age factor had a significant variation $\left(X^{2}=28.23, P=0.000\right)$ in the occurrence of these parasitic infections. From the total faecal samples, 49 samples were diarrheic and 335 were nondiarrheic. $97.9 \%$ and $3.7 \%$ were positive from diarrheic and non-diarrheic faecal samples, respectively, which is significantly $\left(X^{2}=64.91, P=0.000\right)$ associated with these parasite infections (Table 1).

\section{Discussion}

The present study revealed that the overall prevalence of Ascaris and Heterakis was $44.5 \%$ in local and exotic chickens managed under an extensive and intensive

Table I Risk Factors Associated with Helminthes Infections Among Screened Poultry

\begin{tabular}{|c|c|c|c|c|c|c|}
\hline & & No. Examined Animals & No. Positive Cases & Prevalence (\%) & & \\
\hline Breed & $\begin{array}{l}\text { Indigenous } \\
\text { Exogenous } \\
\text { Total }\end{array}$ & $\begin{array}{l}170 \\
214 \\
384\end{array}$ & $\begin{array}{l}114 \\
57 \\
171\end{array}$ & $\begin{array}{l}67.1 \\
36.3 \\
44.5\end{array}$ & $X^{2}=62.73$ & $P=0.000$ \\
\hline Production system & $\begin{array}{l}\text { Intensive } \\
\text { Extensive } \\
\text { Total }\end{array}$ & $\begin{array}{l}41 \\
343 \\
384\end{array}$ & $\begin{array}{l}10 \\
161 \\
171\end{array}$ & $\begin{array}{l}24.4 \\
46.9 \\
44.5\end{array}$ & $X^{2}=7.54$ & $P=0.006$ \\
\hline Age & $\begin{array}{l}\text { Below } 5 \text { months } \\
\text { Above } 5 \text { months } \\
\text { Total }\end{array}$ & $\begin{array}{l}90 \\
294 \\
384\end{array}$ & $\begin{array}{l}62 \\
109 \\
171\end{array}$ & $\begin{array}{l}68.9 \\
37.1 \\
44.5\end{array}$ & $X^{2}=28.23$ & $P=0.000$ \\
\hline Faecal concentration & $\begin{array}{l}\text { Diarrheic } \\
\text { Non Diarrheic } \\
\text { Total }\end{array}$ & $\begin{array}{l}49 \\
335 \\
384\end{array}$ & $\begin{array}{l}48 \\
123 \\
|7|\end{array}$ & $\begin{array}{l}97.9 \\
36.7 \\
44.5\end{array}$ & $X^{2}=64.91$ & $P=0.000$ \\
\hline
\end{tabular}


production system. This finding was comparable with a previous study held in and around Bahir Dar by Beyene et $\mathrm{al}^{1}$ who reported (46.9\%) prevalence of GI nematode in chickens. Local chickens receive their nutrient requirements by roaming around the place, and they normally seek their food in the superficial layers of the soil, which are often polluted with infective stages of parasites and their intermediate hosts. As a result, the constant exposure of chickens to free-range circumstances may aid the spread of parasite illnesses.

The current study's findings, however, were lower than those of Magwisha et $\mathrm{al}^{9}$ who reported a $100 \%$ prevalence of helminth in Tanzania, and Abdullah, ${ }^{15}$ who reported a $100 \%$ prevalence of Gastro-Intestinal parasites in Bangladesh. In four districts of the Amhara region, Eshetu et $\mathrm{al}^{16}$ found a prevalence of (91.01\%). In Kenya, Irungu et $\mathrm{al}^{17}$ found a prevalence of helminthiasis as 90.78\%; in central Ethiopia, Ashenafi and Eshetu ${ }^{6}$ found a prevalence of endoparasitism of $90.21 \%$; and in Bahir Dar, Belete and Addis ${ }^{18}$ found a prevalence of GIT helminths of $84.6 \%$. Molla et $\mathrm{al}^{19}$ in the North Gondar administration zone and Shiferaw et $\mathrm{al}^{20}$ in and around Ambo, West Shewa zone also reported high prevalence of chicken gastrointestinal parasite similarly.

The present prevalence finding was somewhat higher than the reports of gastrointestinal parasites by Negash et $\mathrm{al}^{21}$ in and around Hawassa town (20.10\%); Afolabi et $\mathrm{al}^{22}$ in Nigeria (20.5\%); Mungube et $\mathrm{al}^{23}$ in Kenya (20.6\%), Alemayehu et al ${ }^{24}$ in Addis Ababa (23.1\%), and Tesfaheywet et $\mathrm{al}^{7}$ in southeastern Ethiopia (41.4\%).

The disparity in prevalence could be attributable to differences in research area (agro-ecological variation), study years, and sampling and examination procedures. It might also be related to the differences in the management system, control practices in the area, and differences in the season of study (rain or dry). During rainy seasons, the intermediate hosts are increased and lead to a higher prevalence of parasites which need intermediate hosts, but during dry seasons, the opposite is true. The present study was almost performed during the dry season. This might have led to a lower prevalence than other studies.

Ascaridia and Heterakis parasite infections were more prevalent in younger chickens, $68.9 \%$ compared to adult $37.1 \%$ of chickens, and this was a statistically significant variation. This finding was in line with a study in north Gondar town by Gebretensae et $\mathrm{al}^{25}$ who found $68.1 \%$ and $37.5 \%$ of GIT parasite prevalence in young and adult chickens, respectively. Negash et $\mathrm{al}^{21}$ reported that the prevalence rate of GIT parasites is relatively higher in the younger age groups than in the adult age groups in and around Hawassa town. But this finding was not agreed with Beyene et $\mathrm{al}^{1}$ in Bahir Dar, who reported a higher prevalence in adults $(50.6 \%)$ than in growers $(38.9 \%)$. Tesfaheywet et $\mathrm{al}^{7}$ found a higher prevalence of helminthiasis in adults (45.9\%) than in young chickens (38\%).

This disparity in incidence by age could be attributable to variances in chicken immunity. Lower immunity development and, as a result, higher sensitivity of younger hens is a possibility. Many factors, including the age of the chicken, the amount of the infective dose, the age of the infective eggs, and the host's diet, are thought to influence the development of worms in the gut. ${ }^{22}$

The prevalence of Gastro-Intestinal parasites was $46.9 \%$ and $24.4 \%$ in the extensive production systems and intensive production systems, respectively. The difference was statistically significant $\left(X^{2}=7.54, P=0.006\right)$. This finding was in agreement with Magwisha et $\mathrm{al}^{9}$ in Tanzania, who reported a (100\%) prevalence of helminth infections in the free-range system regardless of age and sex, and Abdullah, ${ }^{15}$ in Bangladesh, who reported a (100\%) prevalence of helminth infections in backyard chickens. This high prevalence of helminth infection indicates that all freeranging chickens are sub clinically infected. Beyene et $\mathrm{al}^{1}$ in and around Bahir Dar reported a prevalence between different management systems where a higher infection rate was recorded in the extensive management system than in the intensive management system. Molla et $\mathrm{al}^{19}$ in the north Gondar zone of Ethiopia revealed a high prevalence $(79.62 \%)$ of GIT helminths in the extensive management system. A major contributing factor to the high prevalence of these parasitic infections in extensive management systems may be that a basic free-ranging system allows the chickens to scavenge around the house, which increases the chance of getting these parasitic infections.

\section{Conclusion}

The present study revealed that Ascaris and Heterakis parasites were the major problems for the indigenous chickens in the study areas. It also causes subclinical infections in chickens that may lead to invisible production and economic loss. The results indicated that risk factors such as breed, production system, consistency of fecal sample, and age have contributed to the occurrence of poultry intestinal parasites.

This $44.5 \%$ prevalence in extensive and local chickens suggests that there is minimal health care and 
improper sanitation and it is a major threat to the production and productivity of the chickens. The breed and age of chickens were also predisposing factors to these nematode infections. Therefore, awareness creation should be implemented among poultry producers regarding poultry parasite transmission and their preventive and control options, mainly on proper disposal of poultry droppings.

\section{Study Limitations}

Chicken sex and origin-based analyses were not included in this study. Because the prevalence is determined by the presence or absence of parasitic eggs in feces with comparable appearance, it was unable to determine the prevalence of each parasite separately.

\section{Acknowledgments}

The budget for this work was sponsored by the University of Gondar, which the author gratefully acknowledges. Veterinary Parasitology Laboratory technicians from the University of Gondar provided different 1 supports to ensure the study's success. Finally, Gondar city poultry farm owners were recognized for their generosity and assistance during sample collection procedures.

\section{Disclosure}

The authors report no conflicts of interest in this work.

\section{References}

1. Beyene K, Bogale B, Chanie M. Study on effects and occurrence of nematodes in local and exotic chickens in and around Bahir Dar, Northwest Ethiopia. Am Eurasian J Sci Res. 2014;9:62-66. doi:10.5829/idosi.aejsr.2014.9.3.86148

2. Woldemariam S, Wossene A. Infectious bursal disease (Gumboro disease): case report at Andasa Poultry Farm, Amhara Region. Ethiop Vet J. 2007;11:151-155.

3. ALAMARGOTJ: Avian pathology of industrial farms in Ethiopia. First National Livestock Improvement conference Addis Ababa, Agricultural Research Institute; IAR proceedings; 1987. 114-117.

4. Debella T. Characterization of lesions and evaluation of hematological and serum biochemical changes in scavenging chicken naturally infected by gastrointestinal helminths in and around Bishoftu; 2017. Available from: http://localhost:80/xmlui/handle/123456789/14264. Accessed August 31, 2021.

5. Schwarz A, Gauly M, Abel H, et al. Pathobiology of Heterakis gallinarum mono-infection and co-infection with Histomonas meleagridis in layer chickens. Avian Pathol. 2011;40(3):277-287. doi:10.1080/03079457.2011.561280

6. Ashenafi H, Eshetu Y. Study on gastrointestinal helminths of local chickens in Central Ethiopia. Rev Med Vet. 2004;155:504-507.
7. Tesfaheywet Z, Amare E, Hailu Z. Helminthosis of chickens in selected small scale commercial poultry farms in and around Haramaya Woreda, Southeastern Ethiopia. J Vet Adv. 2012; $2:: 462-468$.

8. Central Statistical Agency Report, National. Available from: http:// catalog.ihsn.org/index.php/catalog/3583/download/50086. Accessed January 10, 2017.

9. Magwisha H, Kassuku A, Kyvsgaard N, et al. A comparison of the prevalence and burdens of helminth infections in growers and adult free-range chickens. Trop Anim Health Prod. 2002;34:205-214. doi:10.1023/A:1015278524559

10. Thrusfield M. Veterinary Epidemiology. 2nd ed. UK: Blackwell science; 2005:178-187.

11. Aljoburi M, Jassim N, Hassan I. OJVRTM. Onl $J$ Vet Res. 2019;23:32-39.

12. Permin Hansen JW. Epidemiology, diagnosis, and control of poultry parasites; FAO. 1998. Available from: http://www.fao.org/3/x0520e/ x0520e.pdf. Accessed August 31, 2021.

13. Soulsby EJL, Helminths, arthropods and protozoa of domesticated animals. London: Bailliere Tindall; 1982. Available from: https://www.cabdirect.org/cabdirect/abstract/ 19682902735. Accessed August 31, 2021.

14. Taylor M, Coop R, Wall R. Veterinary Parasitology. 3rd ed. Oxford, UK: Blackwell Publishing; 2007. Available from: https://www.world cat.org/title/veterinary-parasitology/oclc/85691539.

15. Abdullah S, Barman A, Ali MY, Islam MS, Mohanta UK. Morphological identification and prevalence of gastrointestinal helminths in backyard chicken from selected areas of Bangladesh. Res Agric Livest Fish. 2021;8(1):145-155. doi:10.3329/ralf.v8i1.53276

16. Eshetu Y, Mulualem E, Ibrahim H, Berhanu A, Aberra K. Study of gastro-intestinal helminths of scavenging chickens in four rural districts of Amhara Region, Ethiopia. Rev Sci Tech. 2001;20 (3):791-796. doi:10.20506/rst.20.3.1310

17. Irungu LW, Kimani RN, Kisia SM. Helminth parasites in the intestinal tract of indigenous poultry in parts of Kenya. J S Afr Vet Assoc. 2004;75(1):58-59. doi:10.4102/jsava.v75i1.452

18. Belete A, Addis M. A survey of gastrointestinal helminthes among chickens in Bahir Dar town, Ethiopia. Eur J Appl Sci. 2015;7:64-71. doi:10.5829/idosi.ejas.2015.7.2.94103

19. Molla W, Haile H, Almaw G, Temesgen W. Gastrointestinal helminths of local backyard chickens in North Gondar Administrative Zone, Ethiopia. Rev Med Vet. 2012;163:362-367.

20. Shiferaw S, Tamiru F, Gizaw A, et al. Study on prevalence of helminthes of local backyard and exotic chickens in and around Ambowest Shoa Zone, Oromia Regional State, Ethiopia. J Veter Sci Med. 2016;4(2):4.

21. Negash A, Mohamed A, Wondimu K. Study on prevalence and risk factors associated with poultry coccidiosis in and around Hawassa town, South Ethiopia. Br J Poult Sci. 2015;4:34-43. doi:10.5829/ idosi.bjps.2015.4.2.95265

22. Afolabi O, Simon A, Olasunkanmi OA. Intestinal parasites of domestic chickens (Gallus gallus domesticus) in Akure, Nigeria. $J$ Biomed. 2016;1:1-4. doi:10.5812/JMB.9771

23. Mungube E, Bauni S, Tenhagen B, et al. Prevalence of parasites of the local scavenging chickens in a selected semi-arid zone of Eastern Kenya. Trop Anim Health Prod. 2008;40:101-109. doi:10.1007/ s11250-007-9068-3

24. Alemayehu T, Tekeselassie A, Kassa S. Prevalence study of poultry coccidiosis in small and large-scale farms in Addis Ababa, Ethiopia. Sci J Crop Sci. 2012;1:26-31.

25. Gebretensae H, Gebreyohannes M, Tesfaye A. Prevalence of poultry coccidiosis in Gondar Town, North West Ethiopia. Am Eurasian J Sci Res. 2014;9:129-135. 


\section{Publish your work in this journal}

Veterinary Medicine: Research and Reports is an international, peerreviewed, open access journal publishing original research, case reports, editorials, reviews and commentaries on all areas of veterinary medicine. The manuscript management system is completely online and includes a very quick and fair peer-review system. Visit http://www.dovepress.com/testimonials.php to read real quotes from published authors.

Submit your manuscript here: http://www.dovepress.com/veterinary-medicine-research-and-reports-journal 